\title{
The effect of parenteral selenium on outcomes of mechanically ventilated patients following sepsis: a prospective randomized clinical trial
}

Legese Chelkeba 1,2,3,4, Arezoo Ahmadi², Mohammad Abdollahi ${ }^{3}$, Atabak Najafi², Mohammad Hosein Ghadimi Reza Mosaed ${ }^{3}$ and Mojtaba Mojtahedzadeh ${ }^{1,2,3^{*}}$

\begin{abstract}
Background: Sepsis and septic shock is characterized by oxidative stress that mainly promotes systemic inflammation and organ failure due to excessive free radical production and depletion of antioxidant defenses. Therefore, we investigated the effect of selenium administration on antioxidant status, levels of cytokines and clinical outcomes.

Methodology: This study was a prospective randomized control trial (RCT) whereby patients received selenium as sodium selenite (2 mg IV bolus followed by $1.5 \mathrm{mg}$ continuous infusion for 14 days) plus standard therapy. The control group received standard therapy without selenium. The primary endpoint was 28 -day mortality. The changes in the mean levels of glutathione peroxidase (GPX) activity, IL-6, IL-8 and IL-10, the incidence of ventilator-associated pneumonia (VAP) and other secondary endpoints were also recorded. VAP was broken down into early VAP and late VAP to see the clinical significance of each. We also recorded any adverse outcomes from selenium infusion.

Results: Over 24-month period, 54 patients were recruited and randomized and an intention to treat (ITT) principle was applied (selenium, $n=29$; control, $n=25$ ) in the final analysis. There was no statistically significant difference between the two groups in 28-day mortality although it was lower in the selenium group compared with the control group: 9 (31\%) in the selenium versus 10 (40\%) in the control groups ( $p=0.49)$. At day 0, GPX activity was $0.185 \pm 0.3$ versus $0.19 \pm 0.3 \mathrm{U} / \mathrm{mL}(p=0.9)$, day 3 , GPX activity was $0.52 \pm 0.5$ versus $0.17 \pm 0.2 \mathrm{U} / \mathrm{mL}(p=0.02)$, at day 7 it was $0.55 \pm 0.5$ versus $0.24 \pm 0.3 \mathrm{U} / \mathrm{mL}(p=0.032)$, at day 10 it was $0.62 \pm 0.7$ versus $0.33 \pm 0.4 \mathrm{U} / \mathrm{mL}$ $(p=0.048)$ and at day 14 it was $1.1 \pm 1$ versus $0.89 \pm 1 \mathrm{U} / \mathrm{mL}(p=0.70)$ for the selenium versus control groups, respectively. However, there were no significant differences between the mean plasma levels of all the three inflammatory cytokines at any point in time between the two groups. There was a significant reduction in occurrence of VAP in the selenium group compared with the control group (55.2 versus $84 \%, p=0.023$ ), respectively.

Conclusion: High-dose selenium administration within the time frame of early goal-directed therapy was not resulted in reduction of 28-day mortality, but increased the activity of glutathione peroxidase with no effect on the levels of inflammatory cytokines at any point in time in mechanically ventilated septic patients. However, selenium supplementation in mechanically ventilated patients following sepsis was associated with reduced occurrence of VAP. Trial registration: IRCT201212082887N4 at WHO Clinical Trial Registry, August 29, 2014
\end{abstract}

Keywords: Severe sepsis, Septic shock, Selenium, Ventilator-associated pneumonia

\footnotetext{
*Correspondence: mojtahed@tums.ac.ir

1 Department of Clinical Pharmacy, Faculty of Pharmacy, Tehran University

of Medical Sciences, International campus (TUMS-IC), Tehran, Iran

Full list of author information is available at the end of the article
}

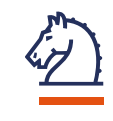

Springer

C 2015 Chelkeba et al. This article is distributed under the terms of the Creative Commons Attribution 4.0 International License (http://creativecommons.org/licenses/by/4.0/), which permits unrestricted use, distribution, and reproduction in any medium, provided you give appropriate credit to the original author(s) and the source, provide a link to the Creative Commons license, and indicate if changes were made. 


\section{Background}

Sepsis constitutes a major health care problem. The incidence of severe sepsis has increased over time and the projected estimate is increased by $1.5 \%$ ever year due to number of reasons [1-3]. Population data suggested that severe sepsis is the leading cause of hospitalization and accounted for $2 \%$ of all hospital admission, with $59 \%$ of the patients requiring admission to the intensive care unit (ICU) [4]. Although the mortality of severe sepsis and septic shock decreased over time, it is still remaining unacceptably high $[3,5]$.

A number of studies suggested that inflammatory cytokines and oxidative stress released during sepsis were higher in septic patients and their concentrations were associated with severity and evolution of organ dysfunctions and death [6-9]. In the initial phase of the disease, there is an overwhelming inflammation, whereby migration of the neutrophils into the inflamed tissue releases free radicals that damage the endothelium and epithelium tissue leading to capillary congestion, leukocyte and macrophage infiltration into the site of inflammation of the respiratory system leading to respiratory failure [10]. Consequently, they acquire nosocomial respiratory tract infections after $48 \mathrm{~h}$ of mechanical ventilation; ventilatorassociated pneumonia (VAP) [11]. It has been reported that ventilator-associated pneumonia is affecting more than $30 \%$ of those susceptible patients and increasing morbidity, mortality, length of ICU stay and costs [1215]. Hence, therapies counteracting the inflammation and oxidative stress and the consequences are attractive. One of those therapies seems to be selenium supplementation. Selenium is an essential trace element for the biosynthesis and function of about 25 known selenocysteine containing selenoproteins, located on the catalytic center of most selenoenzymes [16]. One of the best known and characterized redox systems is glutathione complex consisting of the selenium-dependent peroxidases and the thioredoxin reductases $[17,18]$. Study suggested that selenium plays an important role as anti-inflammatory agent by tightly regulating the expression of proinflammatory genes in immune cells $[19,20]$.

Low plasma selenium levels are associated with an increasing risk of nosocomial infections [21]. Daily infusion of $1600 \mu \mathrm{g}$ selenium following initial bolus dose of $2000 \mu \mathrm{g}$ for 10 days was also found to be a novel therapy that increases Se status, improves illness severity, and lowers the incidence of hospital-acquired pneumonia for systemic inflammatory response syndrome (SIRS) patients in ICU [10]. However, randomized trials and their pooled data involving parenteral selenium supplementation in critically ill patients with sepsis have yielded contradictory results [22-26]. Currently, we do not have concrete evidences that support the administration of selenium in septic patients. Therefore, doing trials that incorporated biomarkers to optimize treatment effects could build the bodies of literatures and help clinicians that need evidence-based medicine. We hypothesized selenium administration within the time frame of early goal-directed therapy in mechanically ventilated patients following sepsis (1) reduces 28-day mortality by $20 \%$ (2) reduces oxidative stress and inflammation (3) reduces ventilator-associated pneumonia.

\section{Methods}

\section{Study design and patient selection}

This was a prospective, randomized, single blind, single center clinical trial conducted on 54 septic patients admitted to ICU of Sina Hospital of Tehran University of Medical Sciences (TUMS). Consecutive patients were recruited from 2012 to December 2014. The study was conducted in accordance with the declaration of Helsinki and approved by the ethics committee of Tehran University of Medical sciences international campus (TUMS-IC) [code of ethical approval: 1-1: 90-3-29]. Oral and written informed consent was obtained from the patients or their close relatives. Moreover, an identification code was used instead of patient's name to protect the patient's identity when reporting trial-related data.

\section{Inclusion and exclusion criteria}

We included patients of age $\geq 17$ years with sepsis, severe sepsis and septic shock, enrolled into the study after diagnosis within $6 \mathrm{~h}$, if the patient was on mechanical ventilation $>48 \mathrm{~h}$ and if they had informed consent either from the patient or the relative. On the other hand, patients were excluded if they were of age $<17$ years, if they were pregnant, if they had missing informed consent either from the patient or the relative, if they participated before in this clinical trial, if they had cancer as the cause of SIRS or sepsis, chronic kidney diseases and if medical staff decided to limit care.

\section{Randomization and protocol}

Consecutive eligible patients were recruited and randomized via block randomization into four blocks, in which a random selection was done using a list of numbers generated using statistical software. Half of the patients in each block were allocated to selenium and the remaining half to control group. Boxes containing the whole treatment for each patient were delivered to the investigator by the hospital pharmacist following the order of the randomization list. All patients remained blinded throughout the study period. Standard treatments for severe sepsis and septic shock were given according to the surviving sepsis campaign (SSC) [27] guidelines. Patients in selenium group were received $2000 \mu \mathrm{g}$ of sodium selenite in 
$100 \mathrm{~mL}$ of normal saline within the first $6 \mathrm{~h}$ of diagnosis of sepsis during $1 \mathrm{~h}$ intravenously followed by $1500 \mu \mathrm{g}$ of sodium selenite in $250 \mathrm{~mL}$ of normal saline during $12 \mathrm{~h}$ continuously for 14 days. The control groups received standard therapy without selenium. Patients otherwise were treated according to the best practice of the hospital, including parenteral or enteral nutrition together with vitamins and trace elements as necessary. The intervention drug was supplied by Biosyn Arzneimittel $\mathrm{GmBH}$ (Fellbach, Germany).

\section{Definitions}

Sepsis, severe sepsis and septic shock were defined according to criteria proposed by the American College of Chest Physicians/Society of Critical Care Medicine [28]. Standard treatments for severe sepsis and septic shock were implemented as following: measurement of lactate levels, appropriate diagnosis studies to ascertain causative organisms before starting antibiotics, early administration of broad spectrum antibiotic therapy, early fluid administration to target Central Venous Pressure (CVP) of 8-12 mmHg and central venous oxygen saturation $\left(\mathrm{SvO}_{2}\right)>70 \%$, hypotension control with vasopressor [27]. Additional works accomplished within $24 \mathrm{~h}$ as appropriate were low dose steroid, glycemic control (blood glucose $<150 \mathrm{mg} / \mathrm{dL}$ ), lung protective ventilation and standard prophylactic measures for deep vein thrombosis (DVT) and stress related mucosal damage (SRMD). We defined VAP as pneumonia that occurs 48-72 $\mathrm{h}$ or thereafter following endotracheal intubation, characterized by the presence of a new or progressive infiltrate, signs of systemic infection (fever, altered white blood cell count), changes in sputum characteristics, and quantitative detection of a causative agent; early VAP $<5$ days, late VAP $\geq 5$ days of mechanical ventilation [29]. SOFA respiratory score was calculated based on $\mathrm{PaO}_{2} / \mathrm{FiO}_{2}(\mathrm{mmHg})$-SOFA score $<400,1 ;<300,2 ;<200$ and mechanically ventilated, $3 ;<100$ and mechanically ventilated, 4.

\section{Data collection \\ Clinical data}

We recorded the following data: demographic data, vital signs, severity scores by calculating APACHE II score, SOFA score, comorbidities, and type of infection based on culture results.

\section{Laboratory data}

We recorded data on hematological, biochemical data analysis, blood gas (for determination of $\left(\mathrm{PaO}_{2} / \mathrm{FiO}_{2}\right)$, blood cultures and cultures of specimen drawn from the site of infection on randomization and then as appropriate.

\section{Follow-up}

Patients were followed up for 90 day or till they died, depending which happened first. The following variables were collected on days 3, 7, 10 and 14 after randomization: vital signs, SOFA respiratory scores and standard laboratory tests. Cultures of specimens drawn from any new site of infection were performed throughout the ICU stay. Duration of mechanical ventilation, duration of vasopressor support, duration of ICU and hospital stays, the incidences of new infection, incidence of ARDS, 28-day mortality and overall mortality were also recorded. The occurrence of VAP was noted throughout the ICU stay along with any adverse reaction as a result of selenium infusion.

\section{Outcome measures}

The primary outcome was 28-day mortality. Changes in GPX activity, IL-6, IL-8 and IL-10 in different points in time of study, duration of mechanical ventilation, duration of ICU and hospital stays and incidence VAP. We also evaluated VAP as early VAP versus late VAP and the effect of each on some clinical outcomes and health care resource consumption measures.

\section{Sample collection, handling and analysis}

Blood samples (5 mL each) were taken from central venous catheters and arterial lines. The first sample was obtained upon diagnosis of sepsis, but prior to initiation of the therapy. Other samples were obtained on days 3, 7,10 , and 14 after randomization. The blood samples were collected into vacutainer tubes containing EDTA and spun these samples at $3000 \times g$ for $10-15 \mathrm{~min}$ to remove cells and cellular debris. The cell-free supernatant and plasma were stored at $-80{ }^{\circ} \mathrm{C}$ until the time of the analyses. The levels of GPX, IL- 6 , IL- 8 and IL-10 were analyzed via automated platinum ELISA kit (Human $\mathrm{Cu}$ / ZnOD, Affymetrix eBioscience, Vienna, Austria) in Massoud laboratory, an independent laboratory found in Northern part of Tehran, Iran following the manufacturing's instruction. All other routine laboratory activities were carried out in the hospital laboratory according to the prescription of the attending clinicians.

The primary end point was 28-day mortality in the selenium groups and control group. A sample size calculation was carried out using these parameters: alpha-level 0.05 , statistical power level 0.8 , anticipated effect size of 0.2 . This resulted to a suggested sample size of 90 patients based on the results of previous study [30]. However, the recruitment process was so slow that we included only 54 patients in our final analysis according to ITT principle. Recruitment process was so slow due to the fact that Sina hospital is trauma center I which gives services for patients referred from other centers in the country. Since 
we are caring for much debilitated patients referred from other centers that require intensive monitoring and our restricted inclusion criteria, we could not get as many patients as we planned.

\section{Statistical analysis}

Discrete variables are expressed as counts (percentage) and continuous variables as mean \pm standard deviation (SD). Categorical data were compared using Fisher's exact test or Pearson Chi-square test. A Kolmogorov-Smirnov test was used to verify the normality of distributions of continuous variables. Continuous variables conforming to a normal distribution were compared using Student's $t$ test otherwise the Mann-Whitney $U$ test was applied. Changes in SOFA respiratory scores and plasma cytokines levels over time as a function of group were analyzed by performing the two-way repeated-measures of variance (ANOVA). $P$ value $<0.05$ was considered as statistically significant.

\section{Results}

\section{Patients' selection and recruitment}

We assessed 364 patients for eligibility, of which 310 patients were excluded for the following reasons: 257 patients were excluded for not fulfilling the inclusion criteria, 2 patients decline not to participate and 51 patients for different reasons as described in detail in Fig. 1. Finally, 54 patients fulfilling the inclusion criteria recruited over a 2 -year period (Selenium $=29$, control $=25$ ) were included in our final analysis according to the ITT principle although selenium was discounted in 3 patients due to rise in serum creatinine by the order of the senior clinician after 2 days of infusion. All patients followed either till they died or for 90 days, whichever happened first.

\section{Patient characteristics at randomization}

There were no significant differences between the two patient groups for the general characteristics at randomization. The median (IQR) age of patients included was 35 (177-82) years for selenium group and it was 41 (19-82) years for the control group, of which 46 patients (85.2\%) were male. The mean SOFA, APACHE II score and $\mathrm{PaO}_{2} /$ $\mathrm{FiO}_{2}$ on the day of admission were similar in both groups. The severity, the site of infection and the type of organism involved did not significantly differ between the two groups at baseline as shown in Table 1 .

\section{Study endpoints}

28-day mortality There was no statistically significant difference between the two groups in 28-day mortality although it was lower in the selenium group compared with the control group; 9 (31\%) in the selenium group compared with $10(40 \%)$ in the control group, $(p=0.49)$.

Change in GPX, IL-6, IL-8 and IL-10 At day 0, GPX activity was $0.185 \pm 0.3$ versus $0.19 \pm 0.3 \mathrm{U} / \mathrm{mL}(p=0.9)$; day 3, GPX activity was $0.52 \pm 0.5$ versus $0.17 \pm 0.2 \mathrm{U} /$ $\mathrm{mL}(p=0.02)$; at day 7 , it was $0.55 \pm 0.5$ versus $0.24 \pm 0.3$ $\mathrm{U} / \mathrm{mL}(p=0.032)$; at day 10 , it was $0.62 \pm 0.7$ versus $0.33 \pm 0.4 \mathrm{U} / \mathrm{mL}(p=0.048)$ and at day 14 it was $1.1 \pm 1$ versus $0.89 \pm 1 \mathrm{U} / \mathrm{mL}(p=0.70)$ for the selenium versus control groups, respectively. The GPX levels reached significant levels at day 3 and continued to rise till day 14 . There were no significant differences between the mean plasma levels of all the three inflammatory cytokines at any point in time between the two groups as shown in Table 2 and Figs. 2, 3, 4.

Clinical outcomes The mean SOFA respiratory scores on the day of randomization $(2.3 \pm 0.8$ versus $2.4 \pm 0.8$, $p=0.82)$ and day $3(2.5 \pm 0.9$ versus $2.4 \pm 0.9, p=0.69)$ were similar in the selenium and control groups, respectively. However, the mean SOFA respiratory scores decreased significantly only in the selenite versus control group, respectively ( $2.1 \pm 1$ versus $2.7 \pm 1, p=0.03)$ at day 7 and ( $1.6 \pm 1.2$ versus $2.5 \pm 0.8, p=0.01)$ day 10 as shown in Fig. 5. VAP was diagnosed in 16 (55.2\%) patient in the selenite group compared with 21 (84\%) patients in the control group, $(p=0.023)$. Early VAP was diagnosed in $15(51.7 \%)$ patients in the selenium group, whereas it was diagnosed in $15(60 \%)$ patients in the control group $(p=0.54)$. On the other hand, late VAP was diagnosed in $5(17.2 \%)$ patients in the selenium group and $11(44 \%)$ in the control group $(p=0.032)$ as described in Table 3.

Effect of VAP on clinical outcomes We also investigated the effect of VAP on the measures of health care resource consumptions such as duration of mechanical ventilation, duration of ICU and hospital stay and days on vasopressor support. Our results showed that there was no significant difference between those with early VAP versus no early VAP in terms of these measures. However, the presence of late VAP significantly increased the duration of mechanical ventilation $(13.3 \pm 1.4$ versus $8.2 \pm 4.8, p<0.0001)$, duration of ICU stay $(33 \pm 17$ versus $16.5 \pm 13, p<0.0001$ ), duration of hospital stay (37 \pm 22 versus $19.3 \pm 15.6, p=0.002)$ and days on vasopressor therapy $(8.3 \pm 5.3$ versus $2.4 \pm 3, p<0.0001)$. Similarly, early VAP had no significant effect on the incidence of reinfection $(p=0.60)$, ARDS $(p=0.47)$ and overall mortality $(p=0.54)$. On the other hand, there was significant difference between patients presented with late VAP versus no late VAP with respect to the incidence of new infection (OR 46; $95 \%$ CI 8-259, $p<0.0001$ ) and overall mortality (OR 10; $95 \%$ CI $0.18-47, p=0.001$ ), without statistically significant effect on the incidence of ARDS $(p=0.087)$ as depicted in Table 4. 


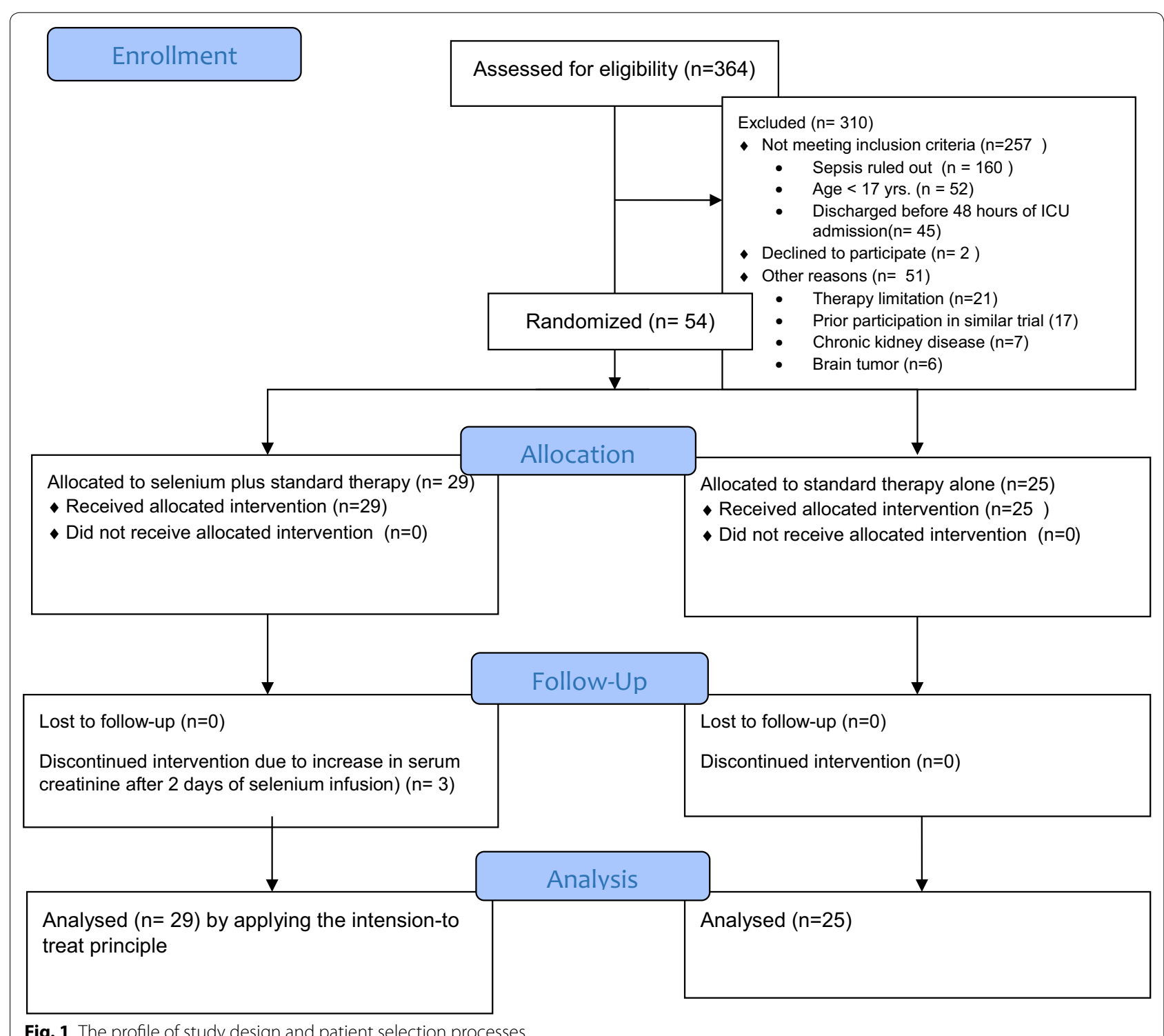

Fig. 1 The profile of study design and patient selection processes

\section{Discussion}

In this study, 54 patients were randomized to standard therapy plus selenium (29 patients) and standard therapy alone ( 25 patients) and included in the final analysis despite discontinuation of selenium in patients due to rise in serum creatinine after 2 days of infusion. The baseline characteristics of the patients included were not significantly differing between the two groups at randomization as described in Table 1 . The most important striking feature in the current study was the inclusion of young patients compared with previously done similar studies [30-33]. Our hospital is a trauma center level I usually giving services for trauma patients. Most of these patients were admitted to the ICU after car/ motorcycle injury and traumatic brain injury (TBI) was the most common one. This group of patients stays in the hospital for longer time and die because of recurrent hospital-acquired infections such as pneumonia and sepsis despite adequate resuscitation and appropriate antibiotic therapy. According to new studies [34-36], early goal-directed therapy versus standard therapy has not changed mortality significantly. That tells us other than fluid and antibiotics, other treatment alternatives may have survival benefits such as high-dose selenium administration.

In this study, we performed a RCT to evaluate the effect of high dose of selenium ( $2 \mathrm{mg}$ IV bolus during $1 \mathrm{~h}$ followed by $1.5 \mathrm{mg}$ continuous infusion for 14 days) on 
Table 1 Demographic and baseline characteristics of study groups

\begin{tabular}{|c|c|c|c|}
\hline Characteristics & Selenium $(n=29)$ & Control $(n=25)$ & $P$ value \\
\hline Age & $35(17-82)$ & $41(19-82)$ & $0.18^{\mathrm{a}}$ \\
\hline Male/female ${ }^{b}$ & $24 / 5$ & $22 / 3$ & 0.59 \\
\hline APACHE $\|^{b}$ & $17 \pm 4.3$ & $16.4 \pm 4.0$ & 0.71 \\
\hline SOFA ${ }^{b}$ & $8 \pm 2.7$ & $8.3 \pm 3$ & 0.69 \\
\hline $\mathrm{PaO}_{2} / \mathrm{FiO}_{2}^{\mathrm{b}}$ & $160 \pm 89$ & $150 \pm 75$ & 0.65 \\
\hline Sepsis, $n(\%)$ & $7(24.1)$ & $6(24)$ & 0.90 \\
\hline Severe sepsis, $n(\%)$ & $8(27.6)$ & $7(28)$ & 0.89 \\
\hline Septic shock, n (\%) & $14(48.3)$ & $12(48)$ & 0.86 \\
\hline Pneumonia, $n$ (\%) & $18(63)$ & $19(76)$ & 0.7 \\
\hline Peritonitis, n (\%) & $7(24)$ & $3(12)$ & 0.20 \\
\hline SSTI infection, $n(\%)$ & $3(10)$ & $2(8)$ & 0.67 \\
\hline CNS infection, $n(\%)$ & $0(0)$ & $1(4)$ & 0.33 \\
\hline CR infection, $n(\%)$ & $1(3)$ & $0(0)$ & 0.32 \\
\hline Gram positive, $n(\%)$ & $4(13.7)$ & $1(4)$ & 0.20 \\
\hline Gram negative, $n(\%)$ & $8(27.6)$ & $9(36)$ & 0.9 \\
\hline No growth, $n$ (\%) & $17(58.7)$ & $15(60)$ & 0.87 \\
\hline
\end{tabular}

APACHE II acute physiological and chronic health evaluation II, SOFA sequential organ failure assessment, SSTI skin and soft tissue, CNS central nervous system, $C R$ catheter line related

a Data given as media (IQR)

b Data given as mean \pm SD

some clinical outcomes. The results of larger, multiplecenter trial confirmed the efficacy of high-dose sodium selenite supplementation in patients with severe sepsis and septic shock in terms of 28-day mortality reduction [30], along with other works [37-41]. This could not be confirmed in our study, as the 28-day mortality was similar in both groups. This could be due to the underpowered nature of the current study. However, our result supported other previously done trials $[22,32]$ and metaanalysis in which selenium supplementation in critically ill patients was not reduced 28-day mortality [24]. The result of our study also showed that administration of selenium resulted in a slight tendency toward decreasing the duration of mechanical ventilation and length of ICU stay with little effect on the length of hospital say. Those who were resuscitated with selenium initially ended up with fewer recurrent pneumonia and sepsis and were weaned quicker due to cardioprotective properties of selenium against reperfusion and reoxygenation which may have led to sepsis-related cardiomyopathy and weaning failure and finally they died as result of sepsisrelated complications.

There are growing interests in carrying out researches in critically ill patients that incorporated biomarkers to optimize the treatment effects. The signaling pathways in inflammation and oxidative stress in vivo are quite complex that in sepsis, there is always a cross talk between
Table 2 Changes in the levels of GPX, IL-6, IL-8 and IL-10 over time period in study patients

\begin{tabular}{|c|c|c|c|}
\hline Biomarker (pg/mL) & Selenium group & Control group & $P$ value \\
\hline \multicolumn{4}{|c|}{ Glutathione peroxidase (U/mL) } \\
\hline GPX on day 0 & $0.185 \pm 0.3$ & $0.19 \pm 0.3$ & 0.90 \\
\hline GPX on day 3 & $0.52 \pm 0.5$ & $0.17 \pm 0.2$ & 0.02 \\
\hline GPX on day 7 & $0.55 \pm 0.5$ & $0.24 \pm 0.3$ & 0.032 \\
\hline GPX on day 10 & $0.62 \pm 0.2$ & $0.33 \pm 0.1$ & 0.048 \\
\hline GPX on day 14 & $1.1 \pm 1$ & $0.89 \pm 1$ & 0.70 \\
\hline \multicolumn{4}{|l|}{ IL-6 (pg/mL) } \\
\hline Day 0 & $43.3 \pm 34$ & $37.8 \pm 35.6$ & 0.61 \\
\hline Day 3 & $25 \pm 28$ & $32.7 \pm 33.3$ & 0.42 \\
\hline Day 7 & $21.6 \pm 27.6$ & $18.6 \pm 24$ & 0.75 \\
\hline Day 10 & $32.5 \pm 31.8$ & $29.8 \pm 33.5$ & 0.82 \\
\hline Day 14 & $30.9 \pm 33.8$ & $31.4 \pm 30$ & 0.97 \\
\hline \multicolumn{4}{|l|}{ IL-8 (pg/mL) } \\
\hline Day 0 & $4.1 \pm 5$ & $4 \pm 5.0$ & 0.95 \\
\hline Day 3 & $5.7 \pm 7.5$ & $4.5 \pm 6.8$ & 0.58 \\
\hline Day 7 & $5.8 \pm 8$ & $5 \pm 6.8 .0$ & 0.78 \\
\hline Day 10 & $4.8 \pm 8$ & $5.8 \pm 5$ & 0.73 \\
\hline Day 14 & $6.1 \pm 8$ & $6.1 \pm 9$ & 0.99 \\
\hline \multicolumn{4}{|l|}{$\mathrm{IL}-10(\mathrm{pg} / \mathrm{mL})$} \\
\hline Day 0 & $4.6 \pm 3$ & $3.6 \pm 2$ & 0.26 \\
\hline Day 3 & $4.6 \pm 3.7$ & $4.2 \pm 4.5$ & 0.76 \\
\hline Day 7 & $3.8 \pm 2.8$ & $5.8 \pm 5.7$ & 0.21 \\
\hline Day 10 & $3.8 \pm 3.5$ & $6.2 \pm 6$ & 0.23 \\
\hline Day 14 & $3.9 \pm 4.6$ & $6 \pm 4.6$ & 0.26 \\
\hline
\end{tabular}

Data presented in mean \pm SD

GPX glutathione peroxidase, IL-6 interleukin-6, IL-8 interleukin-8, IL-10 interleukin-10

inflammation, oxidative stress and coagulation [39]. Measuring the effect of therapy on biomarkers of oxidative stress does not necessarily reflect their effect on inflammatory biomarkers. Currently, we have a number of published articles on the effect of selenium on oxidative stress in septic patients, but we rarely find articles on the effect of this drug on inflammatory cytokines in this group of patients. We investigated the effect of high-dose selenium on GPX activity and inflammatory cytokines such as IL-6, IL-8 and IL-10. Accordingly, selenium administration was associated with significant increase in the plasma activity GPX from day 3 onwards up to day 14 as reported by many previous studies [10, 22, 30, 31] without no effect on the average plasma levels of the after mentioned three cytokines level at any point in time. Although we aimed to evaluate the effect of selenium on the inflammatory response, the study did not provide any new convincing insights into the mechanisms which have already been investigated in different clinical settings [42]. A more productive line of reasoning is as follows: lack of efficacy on cytokines could be due to the small 


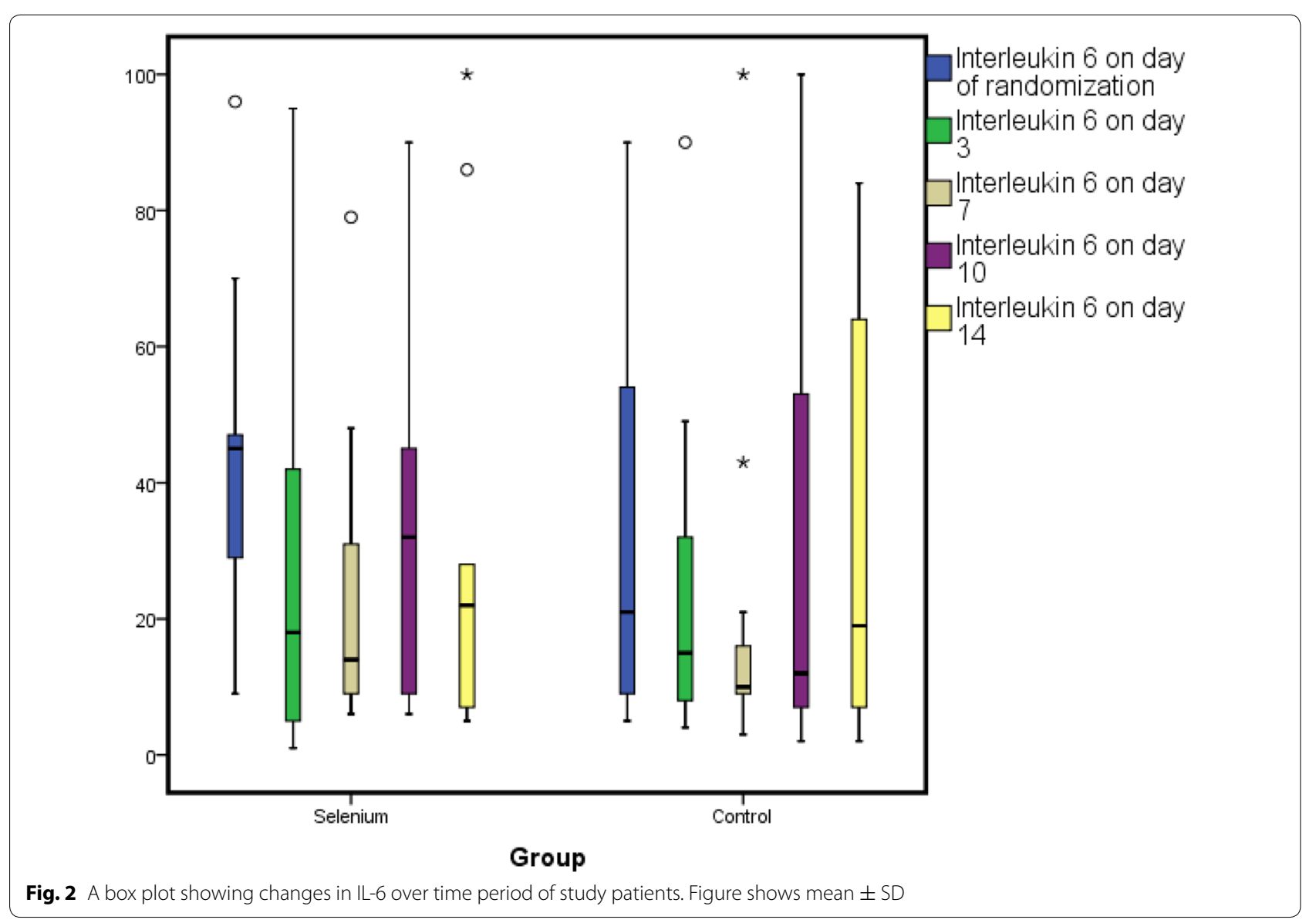

sample size of the study. Second, it seems that monovalent approaches in isolation are unlikely to attain status of complete therapy due to complex interplay between different inflammatory pathways. Saying in another way, it seems that the production and release of sepsis mediators should be considered as a network rather than as a cascade; consequently, once the process is started, even if one of the substances responsible for the initial phase is blocked, other mediators will likely maintain the septic response $[43,44]$. Therefore, as sepsis is such a complex disease process, it is unlike that any single agent can be effective for all patients. A combination strategies-the so-called "cocktail"-can more likely produce definitive results. This can be supported by previous study involving 165 patients requiring mechanical ventilation for sepsis or septic shock. According to this study, patients were randomized to receive enteral nutrition with a standard formula or a study formula that contained higher levels of omega- 3 fatty acids and $\gamma$-linolenic oil, less omega- 6 fatty acids, and higher doses of the antioxidant vitamins $\mathrm{E}$ and $\mathrm{C}$ and selenium. Patients receiving the study formula had an improvement in their mortality rate, oxygenation, ventilator-free days, ICU-free days, and less development of new organ dysfunction [45].

Moreover, the short-half lives and blood levels of cytokines are variable, transit and non-specific so that their measurement might not be viable and effective way of monitoring the efficacy of therapeutic agent. Study by Landenberg $G$ et al. on myocardial dysfunction in 105 severe sepsis and septic shock patients by repeated echocardiograms and concurrent serum inflammatory cytokines (IL-1 $\beta$, IL-6, IL-8, IL-10, IL-18, tumor necrosis factor- $\alpha$, and monocyte chemoattractant protein-1) and cardiac biomarkers [high-sensitivity troponin-T and N-terminal pro-B-type natriuretic peptide (NTproBNP)] measuring showed that none of the measured inflammatory cytokines correlates with systolic or diastolic myocardial dysfunction in this group of patients. The implication of this study is that there may be no correlation between inflammatory cytokines in reallife clinical setting with clinical severity of the diseases. Therefore, the missing effect of selenium on cytokines under consideration does not mean that selenium has no role in septic patients [46]. There is also a hypothesis that 


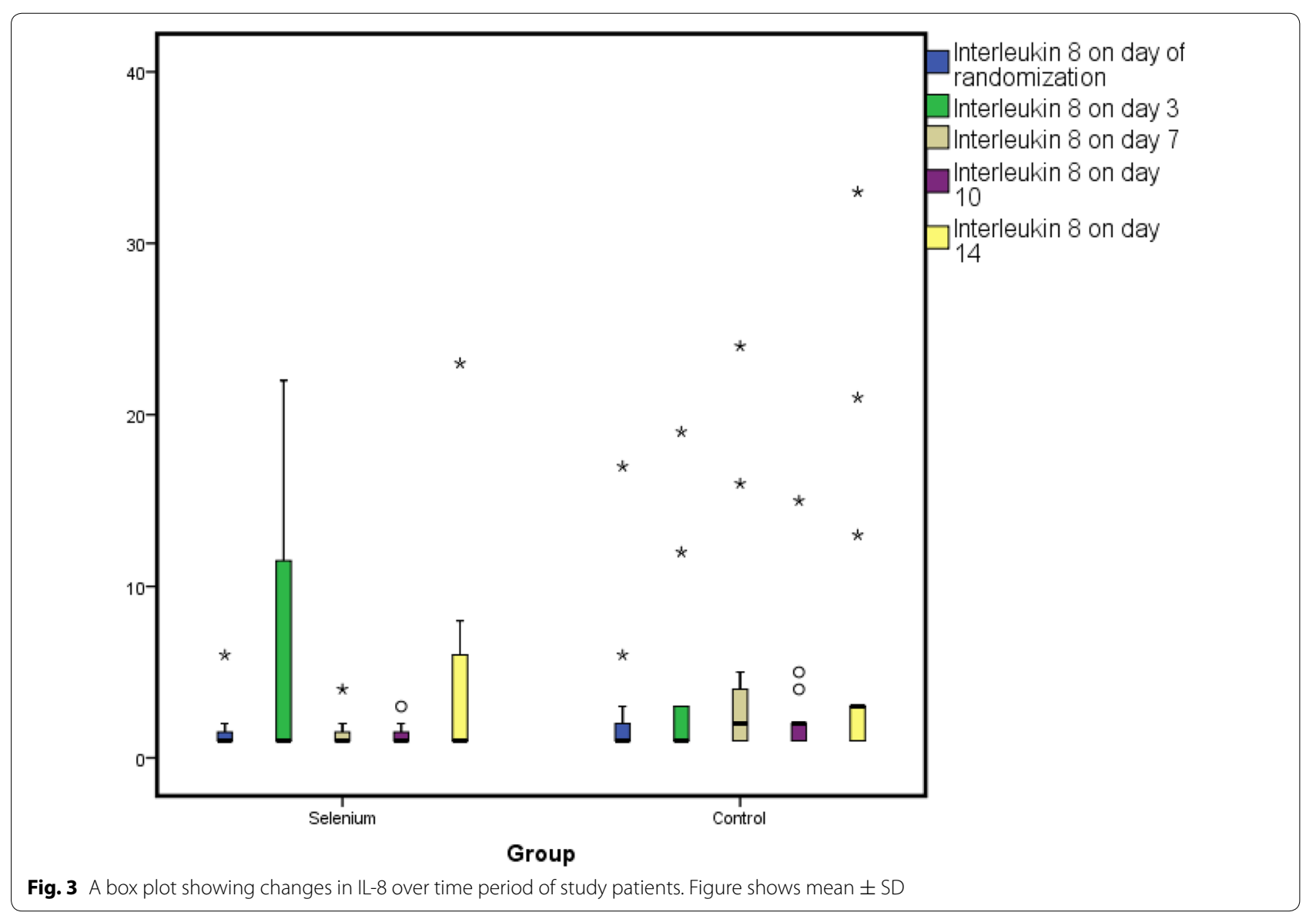

differentiation of CD4 helper cells into $\mathrm{TH} 1$ and $\mathrm{TH} 2$ is dependent on the delicate amount of selenium available. However, Selenium supplementation boosts T cell receptor signals and skews differentiation toward a Th1 phenotype and Selenium deficiency leads to low $\mathrm{T}$ cell receptors signals and skews differentiation toward lowered activation states with a bias toward a Th2 phenotype; adequate selenium intake does not bias $\mathrm{T}$ cell differentiation so that the cytokines released are balanced, which could be the reason why we could not see the effect of selenium in this study [42].

The mean SOFA respiratory scores, which assess the degree of respiratory dysfunction decreased significantly in selenium group, compared with the control on days 7 and 10. This indicates that selenium supplementation in critically ill patients reduces pulmonary infections and thereby improves pulmonary function. A study showed that in patients with severe burn trauma, an adjuvant selenium substitution reduced mainly pulmonary infections [47]. Moreover, the administration of high-dose selenium was associated with significant reduction of occurrence of VAP. Although the occurrence of late VAP was significantly reduced, there was no significant difference with regard to occurrence of early VAP between the two groups; a result opposite with that of Manzanares et al. [33],where selenium supplementation in critically ill patients with SIRS associated with significant reduction in early VAP. The explanation for the discrepancy is that peripheral tissues represent a large and slowly recycling pool. The tissue selenium concentration increases at a lower rate to the normal level compared with the plasma concentration and it begins to increase after selenium supplementation for 2 days and then continues to increase slowly for several weeks [43].Therefore, it makes sense that selenium supplementation slowly increases the intracellular concentration of selenium and the activity of glutathione peroxidase-3, an enzyme that prevents the damaging of endothelial cells and the adherence of bacteria into the respiratory mucosal cells and thereby infection. From this perspective, it is logical if selenium supplementation prevents late-onset VAP which happens in patients after 5 or more days on mechanical ventilation. Nevertheless, it is conceivable from the two studies that the contribution of VAP to mortality and ICU 


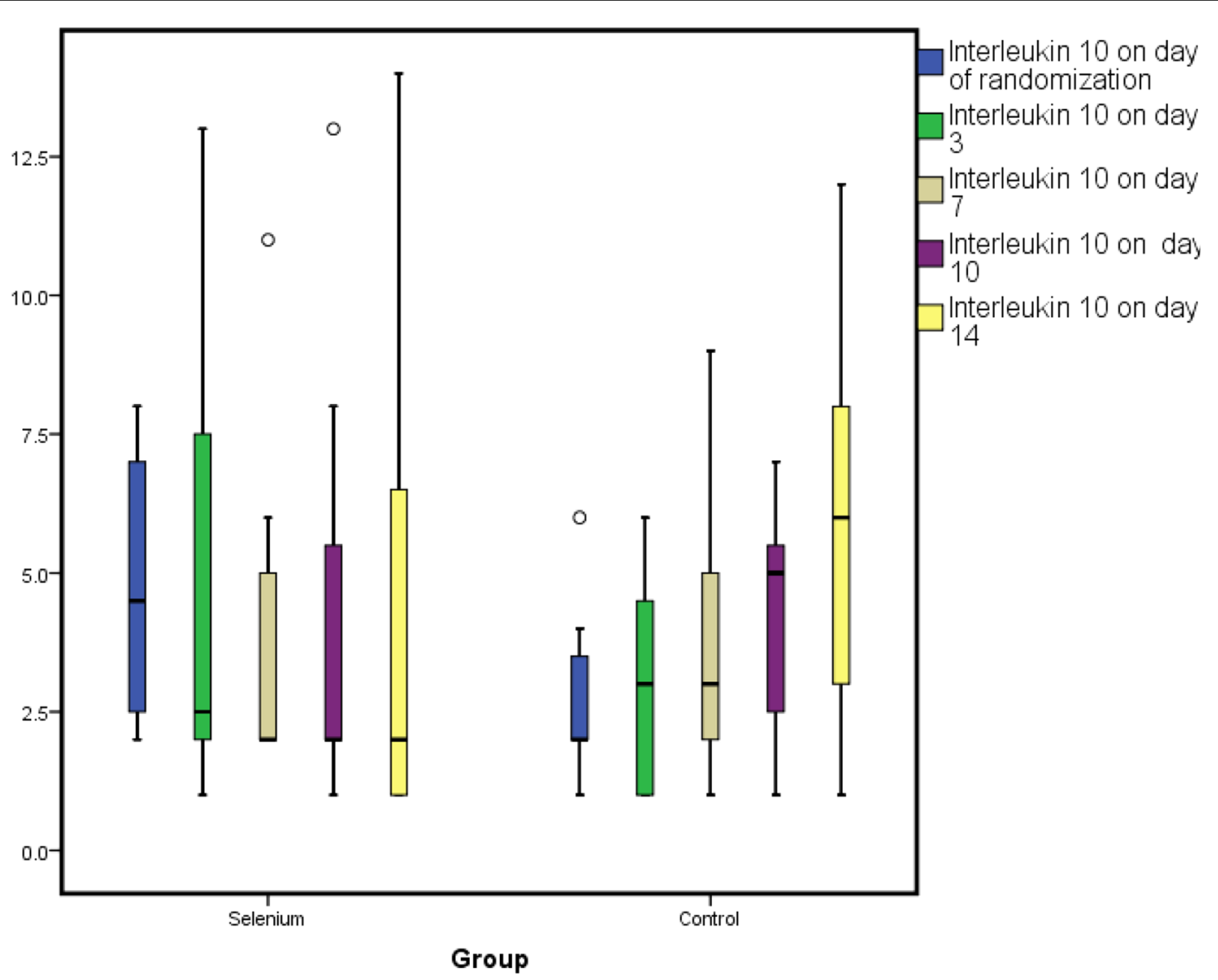

Fig. 4 A box plot showing changes in IL-10 over time period of study patients. Figure shows mean \pm SD

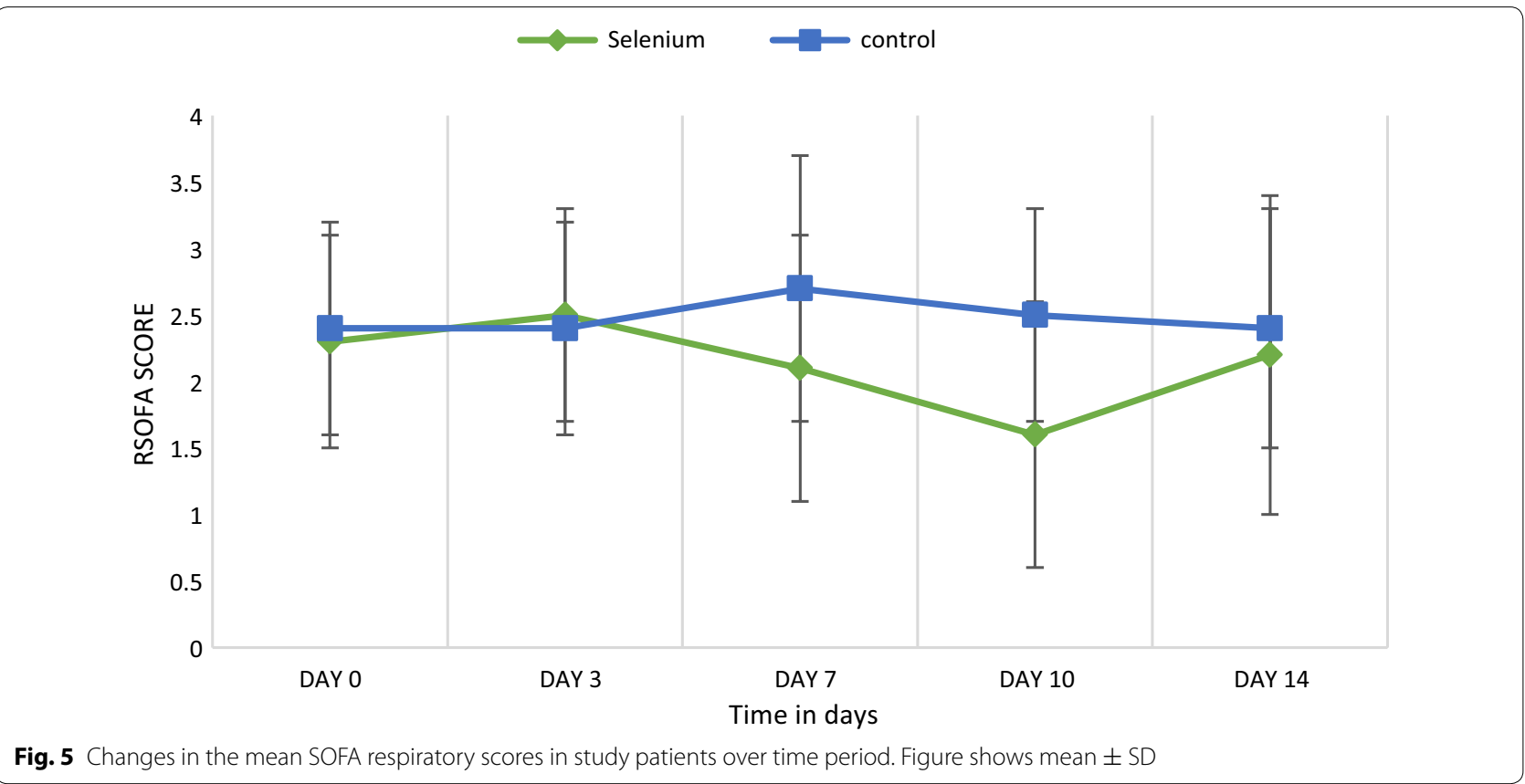


Table 3 Clinical outcomes of study patients

\begin{tabular}{|c|c|c|c|}
\hline Outcome (s) & Selenium group $(n=29)$ & Control group $(n=25)$ & $P$ value \\
\hline \multicolumn{4}{|l|}{ SOFA respiratory score } \\
\hline Day 0 & $2.3 \pm 0.8$ & $2.4 \pm 0.8$ & 0.82 \\
\hline Day 3 & $2.5 \pm 0.9$ & $2.4 \pm 0.9$ & 0.69 \\
\hline Day 7 & $2.1 \pm 1$ & $2.7 \pm 1$ & 0.03 \\
\hline Day 10 & $1.6 \pm 1.2$ & $2.5 \pm 0.8$ & 0.01 \\
\hline Day 14 & $2.2 \pm 1.4$ & $2.4 \pm 0.9$ & 0.77 \\
\hline VAP, $n(\%)$ & $16(55.2)$ & $21(84)$ & 0.023 \\
\hline Early VAP, $n(\%)$ & $15(51.7)$ & $15(60)$ & 0.54 \\
\hline Late VAP, n (\%) & $5(17.2)$ & $11(44)$ & 0.032 \\
\hline Duration of mechanical ventilation (in days), mean \pm SD & $8.9 \pm 5$ & $10.7 \pm 4.5$ & 0.17 \\
\hline Length of ICU stay (in days), mean \pm SD & $19.7 \pm 11$ & $23.8 \pm 13$ & 0.37 \\
\hline Lengths of hospital stay (in days), mean \pm SD & $25.2 \pm 10$ & $24.5 \pm 9$ & 0.87 \\
\hline 28-day mortality, n (\%) & $9(31)$ & $10(40)$ & 0.49 \\
\hline
\end{tabular}

SOFA sequential organ failure assessment, EVAP early ventilator-associated pneumonia, LVAP late ventilator-associated pneumonia, ICU intensive care unit

Table 4 The effect of VAP on clinical outcomes in study patients

\begin{tabular}{|c|c|c|c|c|c|c|c|c|}
\hline \multirow[t]{2}{*}{ Outcome (s) } & \multicolumn{2}{|l|}{ Early VAP } & \multirow[t]{2}{*}{ OR $[95 \% \mathrm{Cl}]$} & \multirow[t]{2}{*}{$P$} & \multicolumn{2}{|l|}{ Late VAP } & \multirow[t]{2}{*}{ OR $[95 \% \mathrm{Cl}]$} & \multirow[t]{2}{*}{$P$ value } \\
\hline & Yes & No & & & Yes & No & & \\
\hline DOMV, mean \pm SD & $10.6 \pm 4$ & $8.6 \pm 5.5$ & & 0.17 & $13.3 \pm 1.4$ & $8.2 \pm 4.8$ & & $<0.0001$ \\
\hline Duration of ICU stay, mean \pm SD & $22.9 \pm 15.5$ & $20 \pm 17.9$ & & 0.54 & $33 \pm 17$ & $16.5 \pm 13.4$ & & $<0.0001$ \\
\hline Duration of hospital stay, mean \pm SD & $25.5 \pm 17$ & $24 \pm 23$ & & 0.78 & $37 \pm 22$ & $19.3 \pm 15.6$ & & 0.002 \\
\hline Days on vasopressor therapy, mean $\pm S D$ & $3.4 \pm 4$ & $5.5 \pm 5$ & & 0.13 & $8.3 \pm 5.3$ & $2.4 \pm 3$ & & $<0.0001$ \\
\hline Incidence of new infection, $n / N$ & $8 / 33$ & $8 / 21$ & $0.6[0.18-2]$ & 0.60 & $13 / 19$ & $3 / 35$ & $46[8-259]$ & $<0.0001$ \\
\hline Incidence of ARDS, n/N & $3 / 33$ & $4 / 21$ & $0.57[0.11-2.8]$ & 0.47 & $4 / 19$ & $3 / 35$ & $3.9[0.76-20]$ & 0.087 \\
\hline Overall mortality, $n / N$ & $16 / 33$ & $13 / 21$ & $0.97[0.33-2.8]$ & 0.54 & $14 / 19$ & $15 / 35$ & $10[1.8-47]$ & 0.001 \\
\hline
\end{tabular}

DOMV duration of mechanical ventilation, ICU intensive care unit, VAP ventilator-associated pneumonia, ARDS acute respiratory distress syndrome, SD standard deviation, $O R$ odds ratio

resource consumption makes prevention an attractive approach, one of which selenium is proposed as novel strategy for inclusion into the bundles for VAP prevention [29]. The damaging of pulmonary interstitial and alveolar spaces in the lung begins with the interaction of immune cells with the endothelial cells, which stimulates the later to express surface adhesion molecules that bind to the neutrophils and facilitate their migration into the interstitial and alveolar spaces. There is also concomitant triggering of free radical bursts into the lungs [33]. Selenium being antioxidant and anti-inflammatory plays a great role here by increasing the activity of glutathione peroxidase. Unfortunately, suboptimal immune function in patients with selenium deficiency was observed, whereby the functions of both innate and acquired immune system impaired and leading to infection, multiple organs failure and hospital-acquired pneumonia [21]. Our study similarly showed that selenium supplementation reduced VAP and reinfection as well. There are also a couple of supporting ideas from Scottish Intensive Care Glutamine or Selenium Evaluative Trial (SIGNET) [23] and Berger et al. $[47,48]$ that enhancing trace elements in critically ill patients is associated with decreased hospital-acquired infections such as episodes of VAP.

Our analyses included versatile directions in that we also did analysis of the effect of VAP on overall mortality, the incidences of reinfection and ARDS and health care resource consumption measures such as duration of mechanical ventilation, duration of ICU and hospital stay, days on vasopressor therapy to explore the indirect beneficial effects of selenium on these clinical outcomes. Accordingly, we found that patients presented with late VAP had significantly longer duration of mechanical ventilation, ICU stay, hospital stay and vasopressor therapy compared to those without late VAP. The presence of late VAP was also associated with higher overall mortality, higher incidence of new infection and ARDS, a result in line with some previously done studies [13, 49-52]. On 
the other hand, there was no significant difference in terms of the mortality, incidence of reinfection or ADRS and resource consumption measures in patients with early VAP compared to those with no early VAP.

Our study has a couple of strengths. First, we administered selenium within the time frame of early goaldirected therapy to evaluate its effect early in sepsis, a strategy found to reduce the mortality rate significantly in patients with severe sepsis and septic shock [53, 54], although this issue becomes a controversial issue at this moment [34-36]. Second, we investigated the effects of VAP on different outcomes on mechanically ventilated septic patients for 5 or more days, which is very important for clinicians caring for such patients to take action ahead of the occurrence and the hospital as a whole to reduce the resource consumption. However, our study was not without limitations. Interpretation of the result of our study should be in caution since our sample size was underpowered to detect the expected differences between the two groups in terms of outcomes. It is also important to mind that our study was single centered which did not include patients from different geographical areas, ethnicity and limited number of females and therefore it perhaps lacked external validity. Furthermore, the study period was relatively long to enroll the required number of participants. Unfortunately, the number of participants enrolled was much below our plan since we are caring for much debilitated patients referred from other centers around that require intensive monitoring and our restricted inclusion criteria. Finally, it is perceivable that the current study was single blind study which could possibly introduce bias to the outcomes.

\section{Conclusion}

High-dose selenium administration within the time frame of early goal-directed therapy was not resulted in reduction of 28-day mortality, but increased the activity of glutathione peroxidase with no effect on the levels of inflammatory cytokines at any point in time in mechanically ventilated septic patients. However, selenium supplementation in mechanically ventilated patients following sepsis was associated with reduced occurrence of VAP. We also observed that late-onset VAP has a significant effect on clinical outcomes and health care resource consumption measures. It is prudent to evaluate the result of this study by an adequately powered, randomized, placebo-controlled trial of high methodological value.

\section{Authors' contributions}

LCH participated in the design and coordination, carried out immunoassay, drafted the manuscript and performed the statistical analysis; AA conceived the study, participated in the design and coordination, and helped to draft the manuscript. MM conceived the study, participated in the design and coordination, helped to draft the manuscript and revised the manuscript. AN participated in the design and coordination of study and revised the manuscript. MA conceived the study and revised the manuscript. MHG and RM participated in the design and coordination, and carried out immunoassay. All authors read and approved the final manuscript.

\section{Author details}

${ }^{1}$ Department of Clinical Pharmacy, Faculty of Pharmacy, Tehran University of Medical Sciences, International campus (TUMS-IC), Tehran, Iran. ${ }^{2}$ Department of Anesthesiology and Critical Care Medicine, Faculty of Medicine, Sina Hospital, Tehran University of Medical Sciences, Tehran, Iran. ${ }^{3}$ Faculty of Pharmacy and Pharmaceutical Sciences Research Center, Tehran University of Medical Sciences, Tehran, Iran. ${ }^{4}$ Department of Clinical Pharmacy, Colleague of Public Health and Medical Sciences, Jimma University, Jimma, Ethiopia.

\section{Acknowledgements}

We would like to thank the fellows, nurses in Sina hospital and laboratory staff of Masoud laboratory for their indispensable help. We also would like to thank Tehran University of Medical sciences, International campus for funding us for doing the trial. Last but not the least, we would like to thank Biosyn Arzneimittel $\mathrm{GmBH}$ (Fellbach, Germany) for providing as sodium selenite for free.

\section{Compliance with ethical guidelines}

Competing interests

The authors declare that they have no competing interests.

Received: 19 June 2015 Accepted: 14 September 2015

Published online: 01 October 2015

\section{References}

1. Angus DC, Linde-Zwirble WT, Lidicker J, Clermont G, Carcillo J, Pinsky MR. Epidemiology of severe sepsis in the United States: analysis of incidence, outcome, and associated costs of care. Crit Care Med. 2001;29(7):1303-10.

2. Annane D, Aegerter P, Jars-Guincestre MC, Guidet B. Current epidemiology of septic shock: the CUB-Rea Network. Am J Respir Crit Care Med. 2003;168(2):165-72.

3. Martin GS, Mannino DM, Eaton S, Moss M. The epidemiology of sepsis in the United States from 1979 through 2000. N Engl J Med. 2003;348(16):1546-54

4. Sands KE, Bates DW, Lanken PN, Graman PS, Hibberd PL, Kahn KL, et al. Epidemiology of sepsis syndrome in 8 academic medical centers. JAMA. 1997;278(3):234-40.

5. Tanriover M, Guven G, Sen D, Unal S, Uzun O. Epidemiology and outcome of sepsis in a tertiary-care hospital in a developing country. Epidemiol Infect. 2006;134(02):315-22.

6. Gogos CA, Drosou E, Bassaris HP, Skoutelis A. Pro-versus anti-inflammatory cytokine profile in patients with severe sepsis: a marker for prognosis and future therapeutic options. J Infect Dis. 2000;181(1):176-80.

7. Cavaillon J-M. Pathophysiological role of pro- and anti-inflammatory cytokines in sepsis. Sepsis. 1998;2(2):127-40.

8. Kurt ANC, Aygun AD, Godekmerdan A, Kurt A, Dogan Y, Yilmaz E. Serum $\mathrm{IL}-1 \beta, \mathrm{IL}-6, \mathrm{IL}-8$, and TNF- $\alpha$; Levels in early diagnosis and management of neonatal sepsis. Mediators of inflammation. 2007. http://www.ncbi.nlm. nih.gov/pubmed/18274637. Accessed July 152015.

9. Oda S, Hirasawa H, Shiga H, Nakanishi K, Matsuda K-I, Nakamua M. Sequential measurement of IL-6 blood levels in patients with systemic inflammatory response syndrome (SIRS)/sepsis. Cytokine. 2005;29(4):169-75.

10. Manzanares WBA, Torre MH, Galusso F, Facchin G, Hardy G. High-dose selenium reduces ventilator-associated pneumonia and illness severity in critically ill patients with systemic inflammation. Intensive Care Med. 2011;37(7):1120-7.

11. Grossman RF, Fein A. Evidence-based assessment of diagnostic tests for ventilator-associated pneumonia: executive summary. Chest J. 2000;117(4_suppl_2):177S-81S.

12. Chastre J, Fagon J-Y. Ventilator-associated pneumonia. Am J Respir Crit Care Med. 2002;165(7):867-903. 
13. Safdar N, Dezfulian C, Collard HR, Saint S. Clinical and economic consequences of ventilator-associated pneumonia: a systematic review. Crit Care Med. 2005;33(10):2184-93.

14. Amin A. Clinical and economic consequences of ventilator-associated pneumonia. Clin Infect Dis. 2009;49(1):36-43.

15. Bouadma L, Sonneville R, Garrouste-Orgeas M, Darmon M, Souweine $B$, Voiriot $G$, et al. Ventilator-associated events: prevalence, outcome, and relationship with ventilator-associated pneumonia. Crit Care Med 2015;43(9):1798-806.

16. Driscoll DM, Copeland PR. Mechanism and regulation of selenoprotein synthesis. Annu Rev Nutr. 2003;23(1):17-40

17. de Vega JMA, Díaz J, Serrano E, Carbonell LF. Oxidative stress in critically ill patients with systemic inflammatory response syndrome. Crit Care Med. 2002;30(8):1782-6.

18. Motoyama T, Okamoto K, Kukita I, Hamaguchi M, Kinoshita Y, Ogawa $H$. Possible role of increased oxidant stress in multiple organ failure after systemic inflammatory response syndrome. Crit Care Med. 2003;31(4):1048-52.

19. Vunta H, Belda BJ, Arner RJ, Channa Reddy C, Vanden Heuvel JP, Sandee pPrabhu K. Selenium attenuates pro-inflammatory gene expression in macrophages. Mol Nut Food Res. 2008;52(11):1316-23.

20. Vunta H, Davis F, Palempalli UD, Bhat D, Arner RJ, Thompson JT, et al. The anti-inflammatory effects of selenium are mediated through 15-deoxy- $\Delta 12$, 14-prostaglandin J2 in macrophages. J Biol Chem. 2007;282(25):17964-73.

21. Forceville $X$, Vitoux D, Gauzit R, Combes A, Lahilaire P, Chappuis $P$. Selenium, systemic immune response syndrome, sepsis, and outcome in critically ill patients. Crit Care Med. 1998;26(9):1536-44.

22. Valenta J, Brodska H, DrabekT, Hendl J, Kazda A. High-dose selenium substitution in sepsis: a prospective randomized clinical trial. Intensive Care Med. 2011;37(5):808-15.

23. Andrews PJ, Avenell A, Noble DW, Campbell MK, Croal BL, Simpson WG, et al. Randomised trial of glutamine, selenium, or both, to supplement parenteral nutrition for critically ill patients. BMJ. 2011;342:1542. http:// www.bmj.com/content/342/bmj.d1542. Accessed July 14, 2015.

24. Kong Z, Wang F, Ji S, Deng X, Xia Z. Selenium supplementation for sepsis: a meta-analysis of randomized controlled trials. Am J Emerg Med. 2013;31(8):1170-5.

25. Miller N, Miller M, Hill LT. The impact of antioxidant supplementation on clinical outcomes in the critically ill: a meta-analysis. South Afr J Crit Care. 2013;29(1):18-26.

26. Visser J, Labadarios D, Blaauw R. Micronutrient supplementation for critically ill adults: a systematic review and meta-analysis. Nutrition. 2011;27(7):745-58.

27. Dellinger RP, Levy MM, Rhodes A, Annane D, Gerlach H, Opal SM, et al. Surviving Sepsis Campaign: international guidelines for management of severe sepsis and septic shock, 2012. Intensive Care Med. 2013;39(2):165-228

28. Bone RC, Balk RA, Cerra FB, Dellinger RP, Fein AM, Knaus WA, et al. Definitions for sepsis and organ failure and guidelines for the use of innovative therapies in sepsis. The ACCP/SCCM Consensus Conference Committee. American College of Chest Physicians/Society of Critical Care Medicine. Chest J. 1992;101(6):1644-55.

29. Rello J, Lode H, Cornaglia G, Masterton R. A European care bundle for prevention of ventilator-associated pneumonia. Intensive Care Med. 2010;36(5):773-80.

30. Angstwurm MW, Engelmann L, Zimmermann T, Lehmann C, Spes CH, Abel $P$, et al. Selenium in Intensive Care $(\mathrm{SIC})$ : results of a prospective randomized, placebo-controlled, multiple-center study in patients with severe systemic inflammatory response syndrome, sepsis, and septic shock*. Crit Care Med. 2007;35(1):118-26.

31. Mishra V, Baines M, Elizabeth Perry S, Jeremy McLaughlin P, Carson J, Wenstone R, et al. Effect of selenium supplementation on biochemical markers and outcome in critically ill patients. Clinical Nutrition. 2007;26(1):41-50.

32. Forceville X, Laviolle B, Annane D, Vitoux D, Bleichner G, Korach J-M, et al. Effects of high doses of selenium, as sodium selenite, in septic shock: a placebo-controlled, randomized, double-blind, phase II study. Crit Care. 2007;11(4):73.

33. Manzanares W, Biestro A, Torre MH, Galusso F, Facchin G, Hardy G. Highdose selenium reduces ventilator-associated pneumonia and illness severity in critically ill patients with systemic inflammation. Intensive Care Med. 2011;37(7):1120-7.

34. Mouncey PR, Osborn TM, Power GS, Harrison DA, Sadique MZ, Grieve RD, et al. Trial of early, goal-directed resuscitation for septic shock. N Engl J Med. 2015;372(14):1301-11.

35. Peake SL, Delaney A, Bailey M, Bellomo R, Cameron PA, Cooper DJ, et al. Goal-directed resuscitation for patients with early septic shock. N Engl J Med. 2014;371(16):1496.

36. Yealy DM, Kellum JA, Huang DT, Barnato AE, Weissfeld LA, Pike F, et al. A randomized trial of protocol-based care for early septic shock. N Engl J Med. 2014;370(18):1683-93.

37. Manzanares W, Dhaliwal R, Jiang X, Murch L, Heyland DK. Antioxidant micronutrients in the critically ill: a systematic review and meta-analysis. Crit Care. 2012;16(2):R66.

38. Landucci F, Mancinelli P, De Gaudio AR, Virgili G. Selenium supplementation in critically ill patients: a systematic review and meta-analysis. J Crit Care. 2014;29(1):150-6.

39. Alhazzani W, Jacobi J, Sindi A, Hartog C, Reinhart K, Kokkoris S, et al. The effect of selenium therapy on mortality in patients with sepsis syndrome: a systematic review and meta-analysis of randomized controlled trials. Crit Care Med. 2013;41(6):1555-64

40. Huang T-S, Shyu Y-C, Chen H-Y, Lin L-M, Lo C-Y, Yuan S-S, et al. Effect of parenteral selenium supplementation in critically ill patients: a systematic review and meta-analysis. PLoS One. 2013;8(1):e54431.

41. Heyland DK, Dhaliwal R, Suchner U, Berger MM. Antioxidant nutrients: a systematic review of trace elements and vitamins in the critically ill patient. Intensive Care Med. 2005;31(3):327-37.

42. Huang $Z$, Rose $A H$, Hoffmann PR. The role of selenium in inflammation and immunity: from molecular mechanisms to therapeutic opportunities. Antioxid Redox Signal. 2012;16(7):705-43.

43. Dinarello CA. Proinflammatory and anti-inflammatory cytokines as mediators in the pathogenesis of septic shock. Chest J. 1997:112(6):321-9.

44. Ulloa L, Tracey KJ. The 'cytokine profile': a code for sepsis. Trends Mol Med. 2005;11(2):56-63.

45. Pontes-Arruda A, Aragão AMA, Albuquerque JD. Effects of enteral feeding with eicosapentaenoic acid, $\gamma$-linolenic acid, and antioxidants in mechanically ventilated patients with severe sepsis and septic shock. Crit Care Med. 2006;34(9):2325-33.

46. Landesberg G, Levin PD, Gilon D, Goodman S, Georgieva M, Weissman C, et al. Myocardial dysfunction in severe sepsis and septic shock-no correlation with inflammatory cytokines in real-life clinical setting. Chest. 2015;148(1):93-102.

47. Berger MM, Baines M, Raffoul W, Benathan M, Chiolero RL, Reeves C, et al. Trace element supplementation after major burns modulates antioxidant status and clinical course by way of increased tissue trace element concentrations. Am J Clin Nutr. 2007;85(5):1293-300.

48. Berger MM, Eggimann P, Heyland DK, Chioléro RL, Revelly J-P, Day A, et al. Reduction of nosocomial pneumonia after major burns by trace element supplementation: aggregation of two randomised trials. Crit Care. 2006;10(6):153.

49. Kollef MH, Silver P, Murphy DM, Trovillion E. The effect of late-onset: ventilator-associated pneumonia in determining patient mortality. Chest J. 1995;108(6):1655-62.

50. Valles J, Pobo A, Garcia-Esquirol O, Mariscal D, Real J, Fernandez R. Excess ICU mortality attributable to ventilator-associated pneumonia: the role of early versus late onset. Intensive Care Med. 2007;33(8):1363-8.

51. Bercault N, Boulain T. Mortality rate attributable to ventilator-associated nosocomial pneumonia in an adult intensive care unit: a prospective case-control study. Crit Care Med. 2001;29(12):2303-9.

52. Moine P, Timsit J-F, De Lassence A, Troché G, Fosse J-P, Alberti C, et al. Mortality associated with late-onset pneumonia in the intensive care unit: results of a multi-center cohort study. Intensive Care Med. 2002;28(2):154-63.

53. Rivers E, Nguyen B, Havstad S, Ressler J, Muzzin A, Knoblich B, et al. Early goal-directed therapy in the treatment of severe sepsis and septic shock. N Engl J Med. 2001;345(19):1368-77.

54. Chelkeba L, Ahmadi A, Abdollahi M, Najafi A, Mojtahedzadeh M. Early goal-directed therapy reduces mortality in adult patients with severe sepsis and septic shock: systematic review and meta-analysis. Indian J Crit Care Med. 2015;19(7):401-11. 